Copyright (C) 2015 by Academic Publishing House Researcher

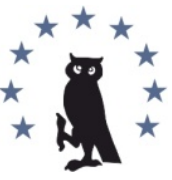

Published in the Russian Federation

European Researcher

Has been issued since 2010 .

ISSN 2219-8229

E-ISSN 2224-0136

Vol. 93, Is. 4, pp. 319-324, 2015

DOI: 10.13187/ er.2015.93.319

www.erjournal.ru

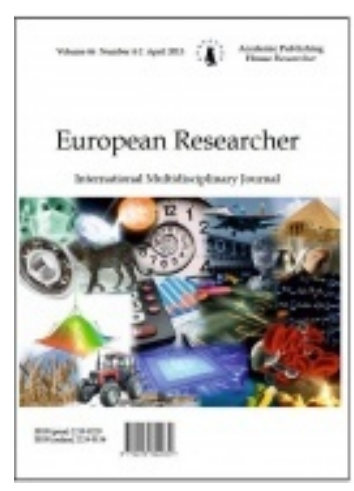

Pedagogical sciences

Педагогические науки

UDC 004:371.13

\title{
The Maintenance of Vocational Training in Terms of Innovative Technologies Development
}

${ }^{1}$ Gulzam Abilkasimova

${ }^{2}$ Ainabek P. Kurymbaev

${ }^{3}$ Kanysh A. Balabekov

${ }^{1}$ Karagandinsky State University. EA Buketova, Kazakhstan

100024 Karaganda, etc. Miners 70, apt. 195

Ph.D., Associate Professor

E-mail: Botam_@mail.ru

${ }^{2}$ Karagandinsky State University. EA Buketova, Kazakhstan

100026 Karaganda, Prospect Stroyteley 1 apt. 190

Senior Lecturer

E-mail: KAynabek@mail.ru

${ }^{3}$ Karagandinsky State University. EA Buketova, Kazakhstan

100028 Karaganda, University Street 18, apt. 20

Senior Lecturer

E-mail: Kanysh-67@mail.ru

\begin{abstract}
The article deals with the maintenance of vocational training in the conditions of the development of innovative technologies, the need for which arises from the fact that today on the future managers and employees are required not only in-depth knowledge, but also the ability to rapidly changing situations to acquire new knowledge and use them to design their own activities and subordinates. For the successful implementation of information technology in the process of training highly qualified specialists of vocational training, it is important to take into account all the possible forms of exposure.
\end{abstract}

Keywords: academic mobility; knowledge-oriented model; innovative technology; training; and teacher professional education specialist; social and cultural development; educational process.

\section{Введение}

Президентом страны Н.А. Назарбаевым четко обозначены приоритеты конкурентоспособности Республики Казахстан через развитие наукоемких и высокотехнологичных производств и внедрение инноваций, что обуславливает 
необходимость переосмысления задач, стоящих перед системой профессионального образования, т.к. без систематического повышения уровня образовательной и профессиональной подготовки рабочих кадров невозможно эффективное применение современной техники и непрерывное внедрение новейших достижений науки [1]. В связи с этим особую актуальность приобретает профессиональная подготовка специалистов в условиях развития инновационных технологий, от которого зависит качество подготовки будущих высококвалифицированных, конкурентоспособных рабочих.

Адаптивность образования, казахстанского педагога к современным реалиям смены целевых, содержательных и процессуальных характеристик в условиях организации личностно-ориентированного образования может быть достигнута лишь переводом школы в инновационный режим развития, адекватного реалиям и тенденциям начала XXI века.

Таким образом, подготовка специалистов на всех уровнях системы профессионального образования в Казахстане в течение последних десяти лет произошли существенные изменения, которые обусловлены экономическими и социальными преобразованиями в обществе. Появилось большое число новых специальностей, возросла потребность в профессионалах, способных успешно работать в условиях рыночной экономики. В связи с этим встает вопрос об изменении процесса подготовки специалистов в высших учебных заведениях в соответствии с задачами, которые ставит рынок труда [2].

В статье мы изложили содержания профессиональной подготовки специалистов в условиях развития инновационных технологий, где необходимость внесения обусловлена тем, что сегодня от будущих руководителей и работников требуются не только глубокие знания, но и умение в быстроменяющейся ситуации приобретать новые знания и использовать их для проектирования собственной деятельности.

\section{Материалы и методы}

В книге К.Ангеловски «Учителя и инновации» приведена цитата из документа OECD/CERI: «Mы считаем, что новшество должно означать попытку изменить систему образования, осуществляемую сознательно и намеренно с целью улучшения нынешней системы. Новшество не обязательно является чем-то новым, но обязательно чем-то лучшим и может быть продемонстрировано само по себе» [3].

На сегодняшний день объем новых знаний увеличивается за год в два раза, поэтому традиционными способами передать и усвоить информацию в полном объеме и прежних временных рамках обучения уже невозможно. Одним из возможных путей решения проблемы является широкое внедрение в практику высших школ эффективных инноваций, основанных на применении новых инновационных технологий. При этом, одной из проблем информатизации профессионального образования является недостаточное количество электронных учебников, учебно-методических пособий и программных средств, использование которых создаст благоприятные условия для повышения качества обучения и позволит развить желание у студентов учиться и самостоятельно добывать знания, будет способствовать творческому развитию личности.

В решение проблем применения информационных технологий в учебном процессе внесли серьезный вклад Б. Абдыкаримов, О.А. Абдуллина, Г.З. Адильгазинов, В.П. Беспалько, В.В. Егоров, В.И. Загвязинский, Г.А. Карпова, В.А. Сластенин, Н.Р. Юсуфбекова, А.А. Андреева, В.В. Васильев, Д.М. Джусубалиева, Т.Х. Дебердеева, Т.К. Клименко, А.И. Севрук, Э.Г. Скибицкий и другие [4-19].

Современный этап развития общества ставит перед системой образования целый ряд новых проблем:

- политическими;

- социально-экономическими;

- мировоззренческими и другими факторами.

Решение данной проблемы мы видим в подготовке педагогов профессионального образования, владеющих технологиями преобразования информации, создания базы данных информационных образовательных ресурсов, разработки электронных учебных изданий, свободно ориентирующихся в информационных потоках, умеющих квалифицированно выбирать, создавать и применять информационно-коммуникативные 
технологии в профессиональной деятельности.

Таким образом, необходимо выделить следующие виды повышения качества и доступности образования.

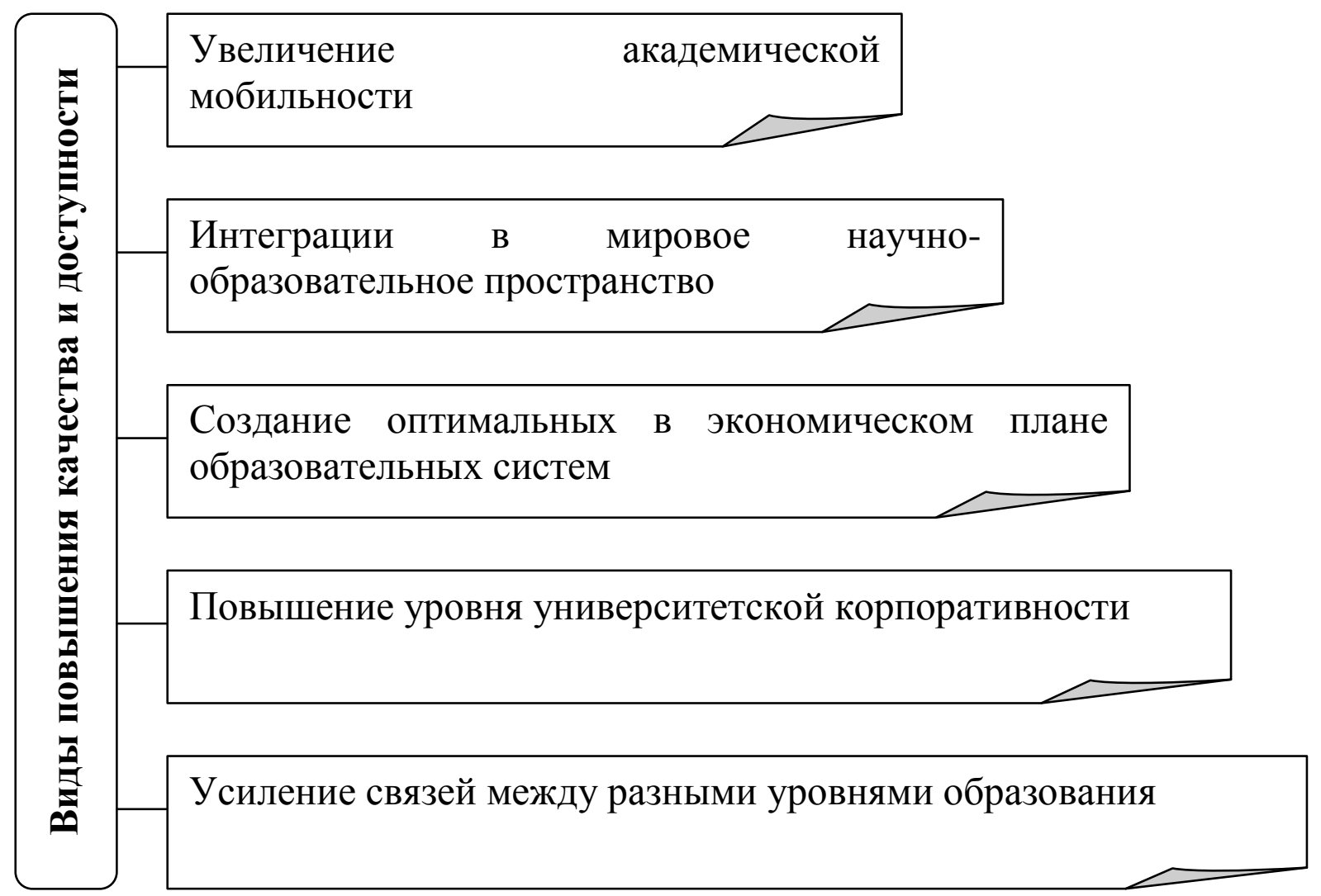

Действительно, многие идеи, высказанные в прошлые годы учеными-педагогами, сохраняют свое значение и сегодня. Их большое влияние на развитие науки и практики никто не оспаривает, однако это не означает, что инновации, сформулированные десятилетия назад, следует считать новыми.

\section{Результаты}

Главной целью содержания профессиональной подготовки специалистов в условиях развития инновационных технологий образования является подготовка человека к жизни в постоянно меняющемся мире. Сущность такого обучения состоит в ориентации учебного процесса на потенциальные возможности человека и их реализацию. Образование должно развивать механизмы инновационной деятельности, находить творческие способы решения жизненно важных проблем, способствовать превращению творчества в норму и форму существования человека.

Основными требованиями к выбору инновационных технологий в новых социальноэкономических условиях являются социально-экономические: удовлетворение потребностей личности в профессиональном образовании различного уровня и высокой степени профессионализма на каждом уровне; обеспечение развития личности, способной влиять на экономическое и социокультурное развитие региона; психолого-педагогические: развитие профессионально важных, социально-значимых умений, качеств личности, способствующих успешному продвижению на каждом уровне образования; развитие мотивации к дальнейшему обучению и дальнейшей профессиональной деятельности в быстро изменяющихся технологических условиях и ее мобильную адаптацию к происходящим научно-техническим и технологическим изменениям.

Целью содержания профессиональной подготовки специалистов в условиях развития инновационных технологий является качественное изменение личности студента по сравнению с традиционной системой. Это становится возможным благодаря внедрению в профессиональную деятельность не известных практике дидактических и воспитательных 
программ, предполагающему снятие педагогического кризиса. Развитие умения мотивировать действия, самостоятельно ориентироваться в получаемой информации, формирование творческого нешаблонного мышления, развитие детей за счет максимального раскрытия их природных способностей, используя новейшие достижения науки и практики, это основные цели развития инновационных технологий.

Для успешного внедрения информационных технологий в процесс подготовки высококвалифицированных специалистов профессионального образования важно принимать во внимание все возможные формы их воздействия. Чтобы правильно строить процесс обучения, достаточно строго определять и оценивать его результаты, осуществлять своевременную коррекцию, развертывать индивидуальные подходы и программы, необходимо владеть технологией проектирования и создания профессорско-преподавательского состава, отвечающих требованиям инновационно-образовательной среды.

Таким образом, содержания профессиональной подготовки специалистов в условиях развития инновационных технологий ориентировано на динамические изменения в окружающем мире, учебная и образовательная деятельность ориентируется на развитие различных форм мышления, творческих способностей. Традиционное образование реализуется «в совершенном исходе из прошлого», а инновационное функционирует в контексте сегодня, ориентируясь на будущее.

\section{Заключение}

На основании выявленных требований информационного общества можно отметить, что содержания профессиональной подготовки специалистов в условиях развития инновационных технологий, по нашему мнению, должно быть направлено не только на обучение универсального и способного к мобильной адаптации к техническому прогрессу специалиста, а на воспитание целостной личности человека-профессионала, стремящегося к постоянному профессиональному и духовному росту и саморазвитию. Качественное отличие педагогических инноваций от инноваций в технической и экономической сферах должно состоять в том, что при их разработке и реализации неприемлема установка на отрыв их от традиции.

Обобщая вышесказанное, можно заключить, что профессиональная подготовка специалистов в условиях развития инновационных технологий выражают интегративное содержание технико-технологических, педагогических, организационно-управленческих, социально-экономических новшеств. Они обеспечивают инновационное развития профессионального образования, а также науки, производства, экономики, управления и социальной сферы. Инновационные процессы в профессионально-педагогическом образовании получают практическое воплощение в инновационном профессиональнопедагогическом образовании, цель которого состоит в подготовке универсальной нравственно зрелой личности, компетентного специалиста с развитой профессиональной культурой, владеющей научным стилем мышления, способной к осуществлению инновационных процессов в профессиональном образовании, производстве, экономике, социуме.

\section{Примечания:}

1. Казахстан-2030. Алматы: ЮРИСТ, 2006. 152 с.

2. Готтинг В.В. Формирование инновационно-технологической компетентности педагога профессионального обучения: автореф.... канд. пед. наук.: Қараганды, 2008. 29 с.

3. Ангеловски К.И. Учителя и инновации: Книга для учителя. М.: Просвещение, 1991. 159 c.

4. Абдыкаримов Б. Профтехшкола и рынок. Алматы, Гылым, 1995. 402 с.

5. Абдуллина О.А. Общепедагогическая подготовка учителя в системе высшего педагогического образования. М.: Просвещение, 1990. 141 с.

6. Адильгазинов Г.З. Теоретические основы совершенствования подготовки учителя к управлению педагогическим процессом в малокомплектной школе: автореф. ... докт.пед.наук: 30.10.02. Алматы: АГУ им. Абая, 2002. 39 с.

7. Беспалько В.П. Основы теории педагогических систем. Воронеж: Изд-во Воронежского университета, 1977. 303 с. 
8. Егоров В.В. Организационно-педагогические основы подготовки инженеровпедагогов для профессионально-трудового обучения учащихся: дисс.... док. пед. наук: Алматы, 1994.

9. Загвязинский В.И. Инновационные процессы в образовании. Тюмень, 1990. 390 с.

10. Карпова Г.А. Интенсификация процесса обучения при помощи автоматизированной обучающей системы. дисс.... канд. пед. наук: Бишкек, 1992. 256 с.

11. Сластенин В.А., Подымова Л.С. Педагогика: инновационная деятельность. М., 1977.

12. Юсуфбекова Н.Р. Общие основы педагогической инноватики: опыт разработки теории инновационных процессов в образовании. М., 1991. С. 10-15.

13. Андреева А.А. Сущность инноваций и инновационной деятельности. http://www. scienceforum.ru

14. Васильев В.В. Информационное обеспечение управление общеобразовательной школой. Воронеж, 1990. 144 с.

15. Джусубалиева Д.М., Мынбаева А.К. Закономерности образовательного процесса и информационное общество // Высшая школа Казахстана. 2000. №1. С. 52-59.

16. Дебердеева T.X. Новые ценности образования в условиях информационного общества // Инновации в образовании. 2005. № 3. С. 79.

17. Клименко Т.К. Инновационное образование как фактор становления будущего учителя. Автореф. Дис. Хабаровск, 2000. 289 с.

18. Севрук А.И. Информационное обеспечение качества образования на муниципальном уровне управления. Педагогика. 2003. № 1. С. 41-46.

19. Скибицкий Э.Г. Компьютеризированные курсы в педагогическом процессе общеобразовательных учреждений. Новосибирск: Институт програмных средств РАН, 1994. $132 \mathrm{c}$.

\section{References:}

1. Kazakhstan-2030. Almaty: YuRIST, 2006. 152 s.

2. Gotting V.V. Formirovanie innovatsionno-tekhnologicheskoi kompetentnosti pedagoga professional'nogo obucheniya: avtoref.... kand. ped. nauk.: Karagandy, 2008. 29 s.

3. Angelovski K.I. Uchitelya i innovatsii: Kniga dlya uchitelya. M.: Prosveshchenie, 1991. 159 s.

4. Abdykarimov B. Proftekhshkola i rynok. Almaty, Gylym, 1995. 402 s.

5. Abdullina O.A. Obshchepedagogicheskaya podgotovka uchitelya v sisteme vysshego pedagogicheskogo obrazovaniya. M.: Prosveshchenie, 1990. $141 \mathrm{~s}$.

6. Adil'gazinov G.Z. Teoreticheskie osnovy sovershenstvovaniya podgotovki uchitelya $\mathrm{k}$ upravleniyu pedagogicheskim protsessom $\mathrm{v}$ malokomplektnoi shkole: avtoref. ... dokt. ped. nauk: 30.10.02. Almaty: AGU im. Abaya, 2002. 39 s.

7. Bespal'ko V.P. Osnovy teorii pedagogicheskikh sistem. Voronezh: Izd-vo Voronezhskogo universiteta, 1977. $303 \mathrm{~s}$.

8. Egorov V.V. Organizatsionno-pedagogicheskie osnovy podgotovki inzhenerov-pedagogov dlya professional'no-trudovogo obucheniya uchashchikhsya: diss.... dok. ped. nauk: Almaty, 1994.

9. Zagvyazinskii V.I. Innovatsionnye protsessy v obrazovanii. Tyumen', 1990. 390 s.

10. Karpova G.A. Intensifikatsiya protsessa obucheniya pri pomoshchi avtomatizirovannoi obuchayushchei sistemy. diss.... kand. ped. nauk: Bishkek, 1992. 256 s.

11. Slastenin V.A., Podymova L.S. Pedagogika: innovatsionnaya deyatel'nost'. M.,1977.

12. Yusufbekova N.R. Obshchie osnovy pedagogicheskoi innovatiki: opyt raz-rabotki teorii innovatsionnykh protsessov v obrazovanii. M., 1991. S. 10-15.

13. Andreeva A.A. Sushchnost' innovatsii i innovatsionnoi deyatel'nosti. http://www. scienceforum.ru

14. Vasil'ev V.V. Informatsionnoe obespechenie upravlenie obshcheobrazovatel'noi shkoloi. Voronezh, 1990. $144 \mathrm{~s}$.

15. Dzhusubalieva D.M., Mynbaeva A.K. Zakonomernosti obrazovatel'nogo protsessa i informatsionnoe obshchestvo // Vysshaya shkola Kazakhstana. 2000. №1. S. 52-59.

16. Deberdeeva T.Kh. Novye tsennosti obrazovaniya $\mathrm{v}$ usloviyakh informatsionnogo obshchestva // Innovatsii v obrazovanii. 2005. № 3. C. 79.

17. Klimenko T.K. Innovatsionnoe obrazovanie kak faktor stanovleniya budushchego 
uchitelya. Avtoref. Dis. Khabarovsk, 2000. 289 s.

18. Sevruk A.I. Informatsionnoe obespechenie kachestva obrazovaniya na munitsipal'nom urovne upravleniya. Pedagogika № 1, 2003. S. 41-46.

19. Skibitskii E.G. Komp'yuterizirovannye kursy v pedagogicheskom protsesse obshcheobrazovatel'nykh uchrezhdenii. Novosibirsk: Institut programnykh sredstv RAN, 1994. $132 \mathrm{~s}$.

УДК 004:371.13

\title{
Содержания профессиональной подготовки специалистов в условиях развития инновационных технологий
}

\author{
${ }^{1}$ Гульзам Абилкасимова \\ ${ }^{2}$ Айнабек Пердекулович Курымбаев \\ ${ }^{3}$ Каныш Аманжолович Балабеков
}
${ }^{1}$ Карагандинский государственный университет им. Е.А. Букетова, Казахстан 100024, Караганда, пр. Шахтеров 70, кв. 195
Кандидат педагогических наук, доцент
E-mail: Botam_@mail.ru
${ }^{2}$ Карагандинский государственный университет им. Е.А. Букетова, Казахстан 100026, Караганда, проспект Строителей 1, кв. 190
Старший преподаватель
E-mail: KAynabek@mail.ru
${ }^{3}$ Карагандинский государственный университет им. Е.А. Букетова, Казахстан 100028, Караганда, ул. Университетская 18, кв. 20
Преподаватель
E-mail: Kanysh-67@mail.ru

Аннотация. В статье рассматривается содержания профессиональной подготовки специалистов в условиях развития инновационных технологий, где необходимость внесения обусловлена тем, что сегодня от будущих руководителей и работников требуются не только глубокие знания, но и умение в быстроменяющейся ситуации приобретать новые знания и использовать их для проектирования собственной деятельности и деятельности подчиненных. Для успешного внедрения информационных технологий в процесс подготовки высококвалифицированных специалистов профессионального образования важно принимать во внимание все возможные формы их воздействия.

Ключевые слова: академическая мобильность; знаниево-ориентированной модель; инновационная технология; профессиональная подготовка; педагог профессионального образования; специалист; социокультурное развитие; учебный процесс. 